\title{
Article
}

\section{Bosoite, a new silica clathrate mineral from Chiba Prefecture, Japan}

\author{
Koichi Momma ${ }^{\star *}$ (D), Takuji Ikeda², Toshiro Nagase ${ }^{3}$, Takahiro Kuribayashi ${ }^{4}$, Chibune Honma ${ }^{5}$, Katsumi Nishikubo ${ }^{6}$, \\ Naoki Takahashi ${ }^{7}$, Masayuki Takada ${ }^{8}$, Yoshitaka Matsushita ${ }^{9}$, Ritsuro Miyawaki ${ }^{1}$ and Satoshi Matsubara ${ }^{1}$ \\ ${ }^{1}$ National Museum of Nature and Science, 4-1-1 Amakubo, Tsukuba, Ibaraki 305-0005, Japan; ${ }^{2}$ National Institute of Advanced Industrial Science and Technology \\ (AIST Tohoku), 4-2-1 Nigatake, Miyagino-ku, Sendai 983-8551, Japan; ${ }^{3}$ Tohoku University Museum, Aoba, Sendai 980-8578, Japan; ${ }^{4}$ Tohoku University, Aoba, Sendai \\ 980-8578, Japan; ${ }^{5} 2345$ Kamisanagura, Tateyama, Chiba 294-0038, Japan; ${ }^{6} 593-3$, Noda, Iruma, Saitama $358-0054$, Japan; ${ }^{7}$ Natural History Museum and Institute, \\ Chiba, 955-2 Aoba-cho, Chuo-ku, Chiba 260-8682, Japan; ${ }^{8}$ Takada Crystal Museum, 456 Haikata, Oharano, Nishikyo-ku, Kyoto 610-1132, Japan; and ${ }^{9}$ National \\ Institute for Materials Science, 1-2-1 Sengen, Tsukuba, Ibaraki 305-0047, Japan
}

\section{Abstract}

Bosoite (IMA2014-023) is a new silica clathrate mineral containing hydrocarbon molecules in its crystal structure. Bosoite can be considered structurally as a silica analogue of the structure- $\mathrm{H}$ gas hydrate, where guest molecules are trapped in cage-like voids constructed of the host framework. The mineral occurs in the Miocene tuffaceous sedimentary rocks at Arakawa, Minami-boso City, Chiba Prefecture, Japan. Bosoite is hexagonal, and it crystallises as an epitaxial intergrowth on chibaite crystals, with the $\{0001\}$ of bosoite parallel to octahedral $\{111\}$ form of chibaite. Crystals are colourless and transparent with vitreous lustre. The calculated density is $2.04 \mathrm{~g} / \mathrm{cm}^{3}$. The empirical formula (based on $2 \mathrm{O}$ apfu and guest molecules assumed as $\left.\mathrm{CH}_{4}\right)$ is $\mathrm{Na}_{0.01}\left(\mathrm{Si}_{0.98} \mathrm{Al}_{0.02}\right)_{\Sigma 1.00} \mathrm{O}_{2} \cdot 0.50 \mathrm{CH}$; the end-member formula is $\mathrm{SiO}_{2} \cdot n \mathrm{C}_{x} \mathrm{H}_{2 x+2}$. Bosoite has the space group $P 6 / \mathrm{mmm}$, with the unit-cell parameters $a=13.9020(3) \AA$, $c=11.2802(2) \AA, V=1887.99(6) \AA^{3}$ and $Z=34$. The crystal structure of bosoite was refined by single-crystal X-ray diffraction and converged to $R_{1}=4.26 \%$ for the average model and $R_{1}=2.96 \%$ for the model where all oxygen sites are split.
\end{abstract}

Keywords: bosoite, new mineral, silica clathrate, chibaite, hydrocarbon, Japan

(Received 15 September 2020; accepted 15 November 2020; Accepted Manuscript published online: 20 November 2020; Associate Editor: Juraj Majzlan)

\section{Introduction}

Silica clathrates (or clathrasils) are zeolite-like materials constructed of pure silica framework structures with small cage-like voids. Melanophlogite, a rare silica mineral first reported from Sicily, Italy in the 19th century (von Lasaulx, 1876), is the first example of a silica clathrate. Melanophlogite's chemical composition was at first considered to be essentially $\mathrm{SiO}_{2}$, and the $>6$ wt.\% $\mathrm{C}, \mathrm{H}$ and $S$ detected by chemical analyses were thought to be impurities of organic matter trapped as inclusions (Skinner and Appleman, 1963). It turned out to have a crystal structure similar to the cubic structure-I gas hydrate that can incorporate organic molecules (Kamb, 1965). Gas molecules such as $\mathrm{CH}_{4}, \mathrm{CO}_{2}, \mathrm{~N}_{2}$ and $\mathrm{H}_{2} \mathrm{~S}$ have been reported in natural melanophlogite and noble gases as well as other small molecules can be incorporated into the cages (Gies et al., 1982; Yagi et al., 2007; Tribaudino et al., 2008). Starting from the 1980 s, a variety of silica clathrates such as melanophlogite, dodecasil-3C and dodecasil-1H, as well as pure silica zeolites (zeosils) have been synthesised successfully and studied (e.g. Gies et al., 1982; Gies 1984, Gerke and Gies, 1984). For each unique

\footnotetext{
*Author for correspondence: Koichi Momma, Email: k-momma@kahaku.go.jp Cite this article: Momma K., Ikeda T., Nagase T., Kuribayashi T., Honma C., Nishikubo K., Takahashi N., Takada M., Matsushita Y., Miyawaki R. and Matsubara S. (2020) Bosoite, a new silica clathrate mineral from Chiba Prefecture, Japan. Mineralogical Magazine 84, 941-948. https://doi.org/10.1180/mgm.2020.91
}

framework topology, the framework type code (FTC) consisting of three capital letters (in bold type) are assigned by the Structure Commission of the International Zeolite Association (IZA-SC) (Baerlocher et al., 2007). The FTC of melanophlogite is MEP.

Chibaite from the Chiba Prefecture, Japan was the second silica clathrate found in Nature (Momma et al., 2011). It has the MTN-type framework structure and it is isostructural with the cubic structure-II hydrate. Associated with chibaite, another silica clathrate mineral that is isostructural with the hexagonal structure-H gas hydrate (Lu et al., 2007) was also found. This mineral has been fully characterised and named as bosoite (Momma et al., 2014). Bosoite is the natural analogue of a synthetic silica clathrate compound with the DOH-type framework structure, known as dodecasil-1H (Gerke and Gies, 1984). The mineral and its name were approved by the International Mineralogical Association (IMA) Commission on New Minerals, Nomenclature and Classification (IMA2014-023). The mineral is named after the Boso Peninsula, the large peninsula just east of Tokyo across the Tokyo Bay. Type material has been deposited in the collections of the National Museum of Nature and Science, Japan, registered number NMS-M43775 and the Tohoku University Museum, Aoba, Sendai, Japan, mineral collection specimen A-153. A single-crystal X-ray diffraction study was done for both the holotype and cotype (NMS-M43763) samples, and data of the cotype are reported here.

(c) The Author(s), 2020. Published by Cambridge University Press on behalf of The Mineralogical Society of Great Britain and Ireland. This is an Open Access article, distributed under the terms of the Creative Commons Attribution licence (http://creativecommons.org/licenses/by/4.0/), which permits unrestricted re-use, distribution, and reproduction in any medium, provided the original work is properly cited. 


\section{Occurrence}

Bosoite occurs in association with chibaite, which was found from Arakawa, Minami-boso City, Chiba Prefecture, Japan (Momma et al., 2011). The Boso Peninsula encompasses the entire Chiba Prefecture located in the middle of the Honshu Island, and Arakawa is located in the south of the Peninsula. Bosoite and chibaite occur in small quartz and calcite veins partly developed at fault planes in tuffaceous sandstone and mudstone of the Miocene Hota Group. They are considered to be a series of forearc sediments deposited near the plate margin by the Palaeo-Izu arc and accreted along the proto-Sagami trough by subduction of the Philippine Sea plate during the Early to Middle Miocene (Ogawa and Ishimaru, 1991; Takahashi et al., 2016).

The sequence of mineral formation from rim to centre of the vein is generally as follows: a very thin layer of clinoptilolite-(Na) and/or opal-A, melanophlogite, chibaite, bosoite and calcite. Melanophlogite 'crystals' were always found as cubic forms of semi-translucent quartz pseudomorphs, with only one exception of an unaltered sample. Many of chibaite 'crystals' are also altered and occur as white quartz pseudomorphs. Some parts of the veins are composed of primary quartz grains or microcrystalline chalcedony. Other associated minerals are pyrite, dachiardite, sepiolite, gypsum and baryte. These minerals were identified by a Gandolfi XRD camera and scanning electron microscopy/energy dispersive X-ray spectrometry (SEM/EDS). The mineral was formed under low-temperature hydrothermal conditions during diagenesis.

\section{Physical and optical properties}

Bosoite occurs as an epitaxial intergrowth on chibaite, where the $\{0001\}$ face of hexagonal bosoite is parallel to the octahedral $\{111\}$ of chibaite (Figs 1 and 2). It exhibits platy shapes parallel to $\{0001\}$. The grain size of an individual crystal is $\sim 0.01 \mathrm{~mm}$ to $0.05 \mathrm{~mm}$ thick and $0.05 \mathrm{~mm}$ to $0.3 \mathrm{~mm}$ in diameter. Crystals are transparent and colourless, have a white streak and a vitreous lustre. Crystals are brittle with an irregular fracture. The Mohs hardness is estimated to be $61 / 2-7$ by scratching a thin section sample by hard metal needles. It is non-fluorescent under shortwave or longwave ultraviolet radiation (254 and $365 \mathrm{~nm}$ ). The density could not be measured because of the small grain size. The calculated density is $2.04 \mathrm{~g} / \mathrm{cm}^{3}$ based on the empirical formula $\mathrm{Na}_{0.01}\left(\mathrm{Si}_{0.98} \mathrm{Al}_{0.02}\right)_{\Sigma 1.00} \mathrm{O}_{2} \cdot 0.50 \mathrm{CH}_{4}$. It is optically uniaxial $(+)$. Due to the small amount of sample available the refractive indices could not be determined. Through observation of the Becke line at grain boundaries between bosoite and chibaite under a polarised light microscope equipped with universal stage, the refractive index $\left(n_{\omega}\right)$ of bosoite was found to be slightly higher than that of chibaite, which is optically isotropic and $n=1.470(1)$.

\section{Raman spectroscopy}

Raman spectra (Fig. 3) were measured using a JASCO NRS-5100 spectrometer. Spectra were obtained using a $532 \mathrm{~nm}$ laser with the 600 grooves $/ \mathrm{mm}$ grating and a $100 \times$ objective lens. A list of Raman shift positions of the hydrocarbon molecules measured in bosoite are given in Table 1 along with those in the free gas state, in chibaite, and in melanophlogite for comparison. The presence of hydrocarbons is shown by bands in the range 2850 to $3050 \mathrm{~cm}^{-1}$. In the $\mathrm{C}-\mathrm{H}$ stretching bands, existence of $\mathrm{CH}_{4}$, $\mathrm{C}_{2} \mathrm{H}_{6}$, and $\mathrm{C}_{3} \mathrm{H}_{8}$ or even larger molecules were detected.
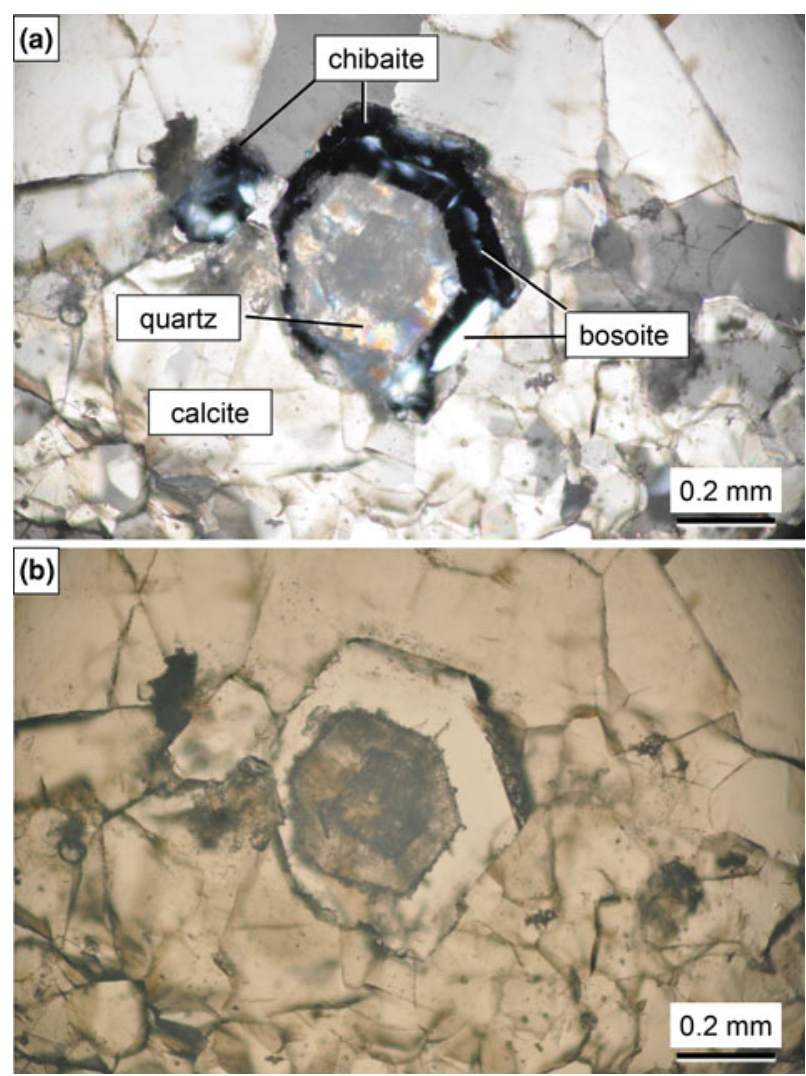

Fig. 1. Photomicrographs of bosoite sample (NSM-M43775) under crossed polarised light (a) and plane polarised light (b). The quartz domain inside chibaite is a pseudomorph of chibaite. The slightly darker area inside the quartz domain is also chibaite overlapped with quartz (see Fig. 2).

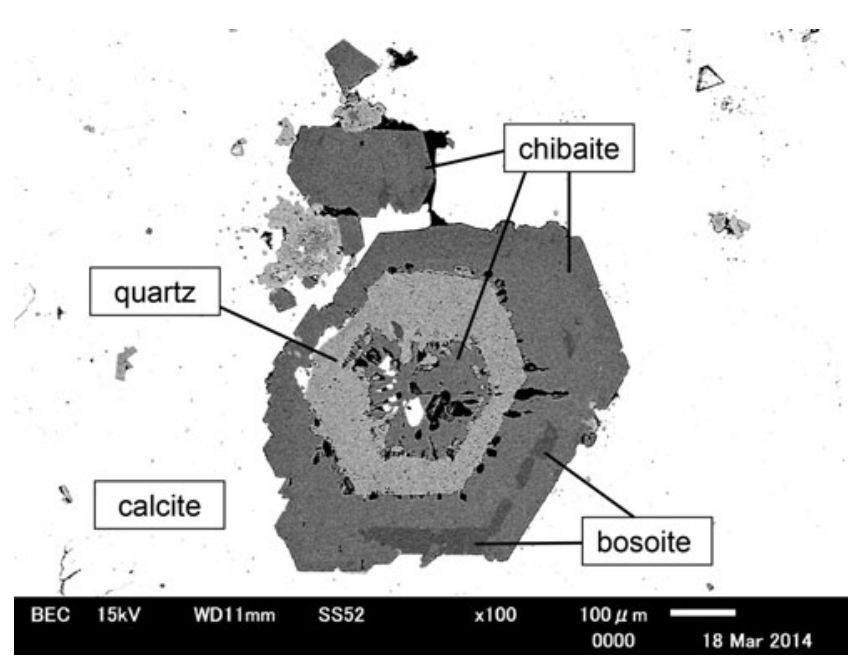

Fig. 2. Back-scattered electron image (BSE) of the sample (NSM-M43775). Bosoite is observed to be slightly darker than chibaite in BSE because the framework density of bosoite (18.0 tetrahedral atoms per $1000 \AA^{3}$ ) is lower than that of chibaite (18.7 tetrahedral atoms per $1000 \AA^{3}$ ).

However, the Raman bands of this region from $\mathrm{C}_{3} \mathrm{H}_{8}$ or larger molecules do not resolve very well. Signals of $\mathrm{C}-\mathrm{C}$ stretching bands $\left(\sim 850-1000 \mathrm{~cm}^{-1}\right)$ could not be detected owing to the high background levels and low signal-to-noise ratios. Therefore, the existence of molecules larger than $\mathrm{C}_{4} \mathrm{H}_{10}$ could 

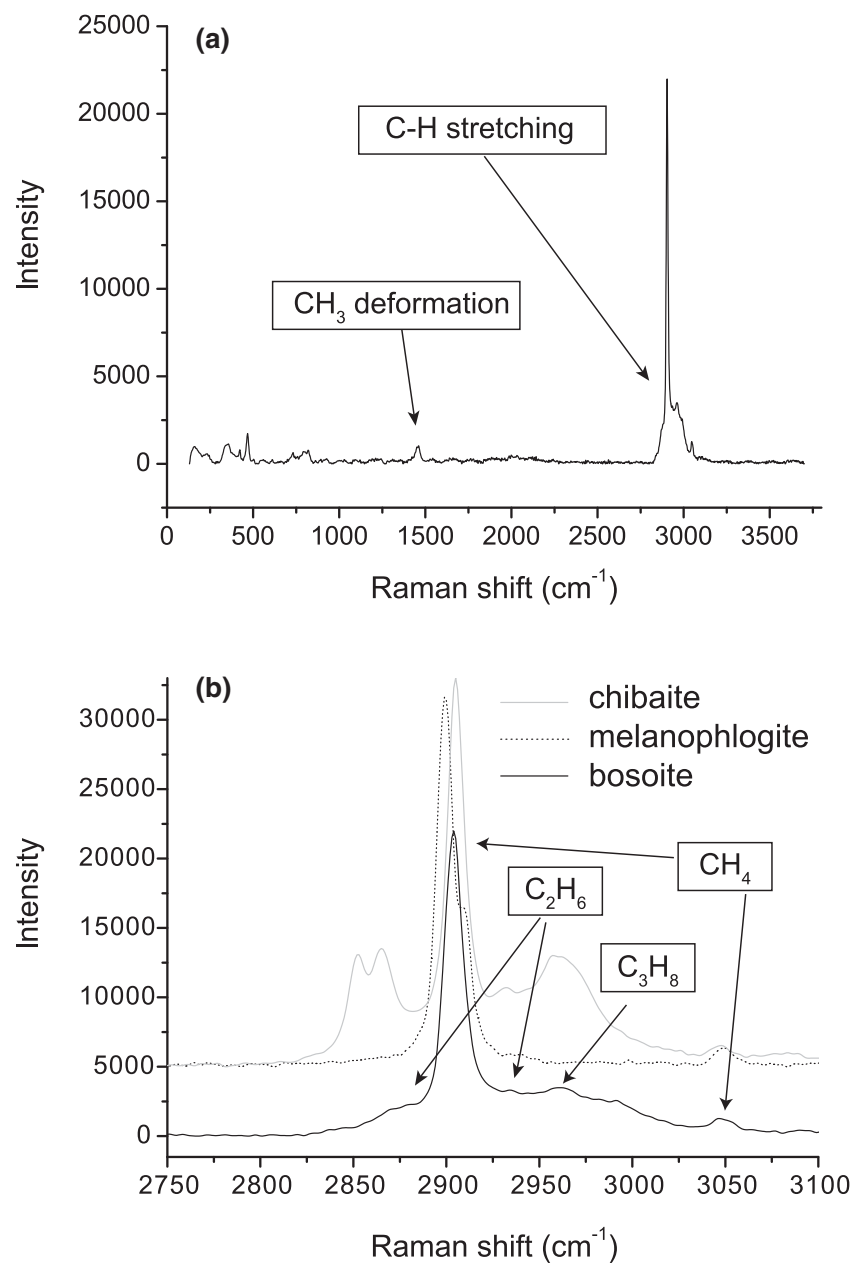

Fig. 3. The Raman spectrum of bosoite (NSM-M43775): (a) the whole measured range and (b) enlarged view of the $\mathrm{C}-\mathrm{H}$ stretching region, overlaid with Raman spectra of chibaite and melanophlogite from the same locality for comparison. Background is subtracted from the data.

not be confirmed. A small peak observed at $1456 \mathrm{~cm}^{-1}$ corresponds to the $\mathrm{CH}_{3}$ degenerate-deformation modes of alkanes with $>2 \mathrm{C}$ atoms. Raman bands of other possible guest molecules, which have been reported in melanophlogite and chibaite, are as follows. $\mathrm{N}_{2}: 2321 \mathrm{~cm}^{-1} ; \mathrm{CO}_{2}: 1277$ and 1378 (Kolesov and Geiger, 2003) or $1380 \mathrm{~cm}^{-1}$ (Kanzaki, 2019); $\mathrm{H}_{2} \mathrm{~S}: 2594$ and
Table 2. Chemical compositions of bosoite.

\begin{tabular}{lcccl}
\hline Constituent & Wt.\% & Range & S.D. & Probe standard \\
\hline $\mathrm{SiO}_{2}$ & 86.38 & $85.10-87.36$ & 0.94 & Quartz \\
$\mathrm{Al}_{2} \mathrm{O}_{3}$ & 1.63 & $1.14-1.96$ & 0.35 & Corundum \\
$\mathrm{Na}_{2} \mathrm{O}$ & 0.34 & $0.32-0.37$ & 0.02 & Jadeite \\
$\mathrm{CH}_{4} / \mathrm{C}_{2} \mathrm{H}_{6} / \mathrm{C}_{3} \mathrm{H}_{8}$ & $11.65^{\star}$ & & & \\
Total & 100.00 & & & \\
\hline
\end{tabular}

${ }^{\star}$ Calculated based on the total. S.D. - standard deviation.

$2604 \mathrm{~cm}^{-1}$ (Tribaudino et al., 2008). Raman bands attributable to guest molecules other than hydrocarbons were not observed in bosoite.

\section{Chemical composition}

Three quantitative chemical analyses were carried out by means of an electron microprobe (JEOL JXA- $8800 \mathrm{M}$, WDS mode, $15 \mathrm{kV}$, $5 \mathrm{nA}$ and $1 \mu \mathrm{m}$ beam diameter). Standard materials for quantitative analyses of the samples were: quartz for $\mathrm{Si}$, corundum for $\mathrm{Al}$ and jadeite for $\mathrm{Na}$. The acquired X-ray intensities were corrected by the ZAF method. The analytical results are given in Table 2. Hydrocarbon contents were not measured directly because of the small amounts of material available and thus their quantitative ratios remain undetermined. The total hydrocarbon is given based on the difference and is reported as $\mathrm{CH}_{4} / \mathrm{C}_{2} \mathrm{H}_{6} / \mathrm{C}_{3} \mathrm{H}_{8}$. The empirical formula (based on $2 \mathrm{O}$ atoms per formula unit with an assumption that all the hydrocarbon is $\mathrm{CH}_{4}$ ), with rounding errors, is $\mathrm{Na}_{0.01}\left(\mathrm{Si}_{0.98} \mathrm{Al}_{0.02}\right)_{\Sigma 1.00} \mathrm{O}_{2} \cdot 0.50 \mathrm{CH}_{4}$.

A suitable simplified formula is not a straightforward choice since, as noted above, a number of guest molecules could be accommodated in the clathrate. Based on the results of the singlecrystal refinement showing a large number of site-scattering factors in the largest cage, the broad Raman bands within the $\mathrm{C}-\mathrm{H}$ stretching region, and previous studies reporting the necessity of large molecules for crystallisation of the DOH-type clathrasil (Gies and Marker, 1992; van Koningsveld and Gies, 2004), hydrocarbon molecules larger than $\mathrm{C}_{4} \mathrm{H}_{10}$ are very likely to be included. Assuming just the presence of alkanes in the mineral, the simplified formula is $\mathrm{SiO}_{2} \cdot n \mathrm{C}_{x} \mathrm{H}_{2 x+2}$, where $x$ denotes average degree of polymerisation for alkanes and the limit of $(n \times x) \leq \sim 0.5$. More details about guest molecules are discussed in the Crystallography section below. The stoichiometry $\mathrm{SiO}_{2} \cdot 0.5 \mathrm{CH}_{4}$ requires $\mathrm{SiO}_{2} 88.22, \mathrm{CH}_{4}$ 11.78 , total 100.00 wt. $\%$.

Table 1. Raman band positions of hydrocarbons in bosoite.

\begin{tabular}{|c|c|c|c|c|c|}
\hline $\begin{array}{l}v_{\text {obs }} \\
\left(\mathrm{cm}^{-1}\right)\end{array}$ & $\begin{array}{l}v_{\text {gas/liquid/solid }} \\
\quad\left(\mathrm{cm}^{-1}\right)\end{array}$ & $\begin{array}{c}v_{\text {(Melanophlogite) }} \\
\left(\mathrm{cm}^{-1}\right)\end{array}$ & $\begin{array}{c}v_{\text {(chibaite) }} \\
\left(\mathrm{cm}^{-1}\right)\end{array}$ & $\begin{array}{c}\text { Assignment } \\
\text { Molecule }\end{array}$ & Vibrational mode \\
\hline 1456 & $\begin{array}{l}1468.1^{\mathrm{e}} \\
1451^{\mathrm{e}} \\
1460^{\mathrm{e}}\end{array}$ & & & $\begin{array}{l}\text { Ethane } \\
\text { Propane } \\
\text { n-Butane }\end{array}$ & $\mathrm{CH}_{3}$ degenerate deformation \\
\hline 2870 & $2900.4^{c}$ & & $2885^{d}$ & Ethane & $\mathrm{C}-\mathrm{H}$ region Fermi resonance doublet bands \\
\hline 2904 & $2917.6^{\mathrm{b}}$ & $\begin{array}{l}2900^{a} \\
2909^{a}\end{array}$ & $\begin{array}{l}2903^{d} \\
2911^{d}\end{array}$ & Methane & $v_{1} \mathrm{C}-\mathrm{H}$ symmetric stretching \\
\hline 2935 & $2955.6^{\mathrm{C}}$ & & $2939^{d}$ & Ethane & \\
\hline 2961 & $\begin{array}{l}2968.7^{\mathrm{e}} \\
2967^{\mathrm{e}} \\
2965^{\mathrm{e}}\end{array}$ & & $2960^{f}$ & $\begin{array}{l}\text { Ethane } \\
\text { Propane } \\
\text { n-Butane }\end{array}$ & $\mathrm{C}-\mathrm{H}_{3}$ degenerate stretching \\
\hline $\begin{array}{l}2992 \\
3049\end{array}$ & & $3047^{\mathrm{a}}$ & $3051^{d}$ & $\begin{array}{l}\text { unassigned } \\
\text { Methane }\end{array}$ & $2 v_{2}$ overtone \\
\hline
\end{tabular}

${ }^{\mathrm{a}}$ Kolesov and Geiger (2003), ' $\mathrm{S}$ um et al. (1997), 'Subramanian et al. (2000), ${ }^{\mathrm{d}}$ Momma et al. (2011), 'Shimanouchi (1972), 'Likhacheva et al. (2016). 


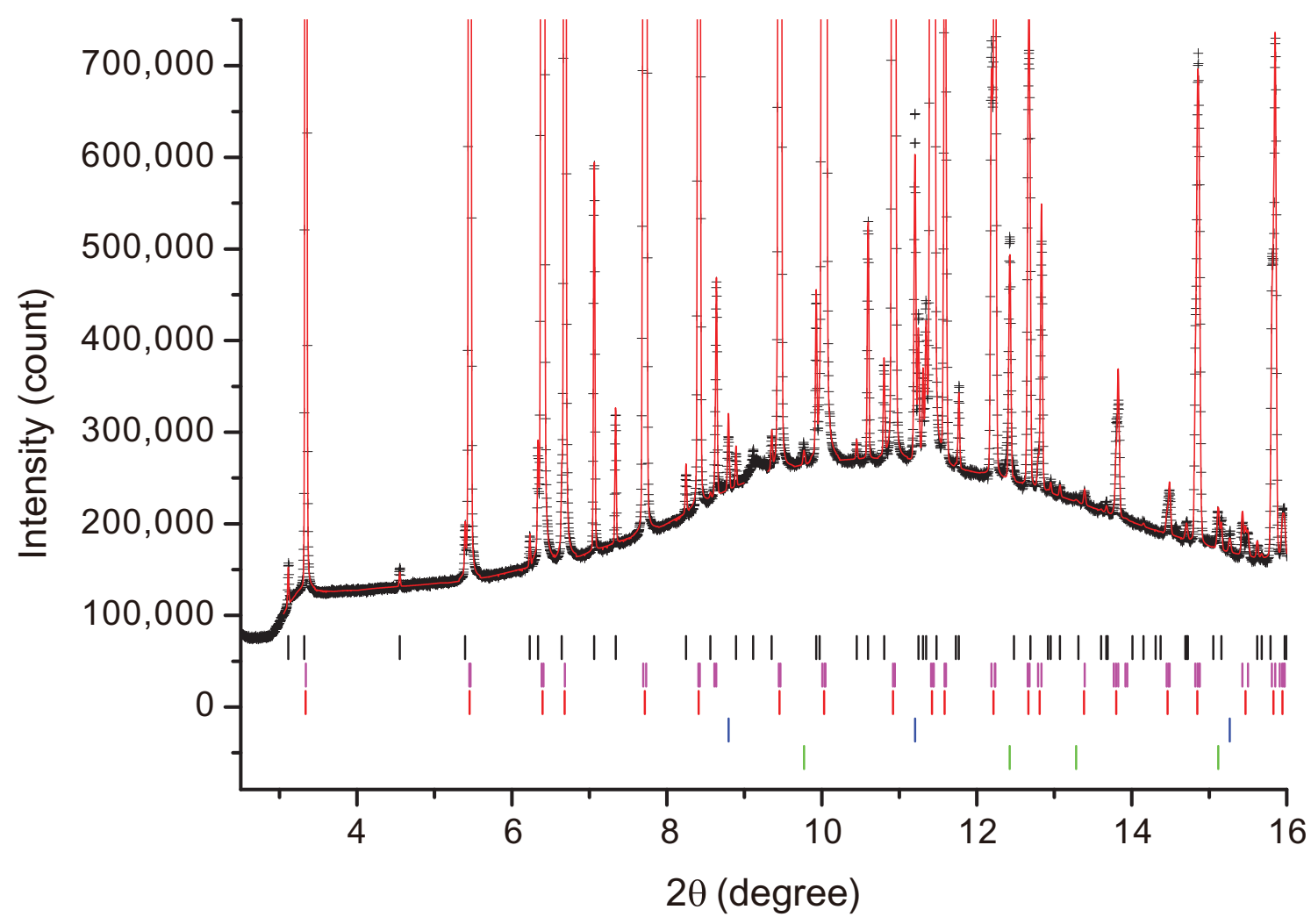

Fig. 4. Observed (black cross) and calculated (solid red line) powder diffraction pattern of sample (NSM-M43775). Tick marks below the pattern indicate diffraction position of bosoite (black), tetragonal phase of chibaite (magenta), cubic phase of chibaite (red), quartz (blue) and calcite (green). Data points from 9.0 to $9.3^{\circ}$ were not used in the refinement because a broad halo from opal-A appearing at this range overlaps with a small bosoite peak. When this data range was used, the halo caused significant overestimate of $I_{\mathrm{o}}$ of the overlapped bosoite peak, leading to drifts of various parameters of bosoite.

\section{Crystallography}

Powder X-ray diffraction (PXRD) data of the holotype sample were collected by the Debye-Scherrer method with synchrotron radiation using an imaging plate at BL15XU, SPring-8, Japan. As bosoite is always associated with chibaite, the chibaite crystals were separated carefully from the host rock and crushed in an alumina mortar. The obtained powder was sealed in a Lindemann glass capillary tube with inner diameter of $0.5 \mathrm{~mm}$. Experimental conditions were as follows: $\lambda=0.652973 \AA$; exposure time $=6 \mathrm{~s}$; and step interval $=0.003^{\circ}$. Data from $3.05^{\circ}$ to $56^{\circ}$ were used for refinement of unit cell parameters by Rietveld analysis using RIETAN-FP (Izumi and Momma, 2007). Atomic coordinates of bosoite were fixed at values reported by Gerke and Gies (1984) and only occupancies of guest sites and isotropic atomic displacement parameters were refined. For chibaite, both the cubic and tetragonal structural models were used because the symmetry of part of chibaite crystals is low (Momma et al., 2011). Although fitting by two structural models for almost perfectly overlapping peaks might have caused overfitting of chibaite parameters, it was still preferable to retrieve better unit-cell parameters of bosoite. The refinement converged to $R_{\mathrm{wp}}=3.41 \%, R_{\mathrm{p}}=$ $2.31 \%$, Gof $=15.17, R_{\text {Bragg }}$ (bosoite $)=4.44 \%, \quad R_{F}$ (bosoite $)=2.09 \%$. Note that the high Gof value is due to extremely high signal / background ratio of data. The refined unit-cell parameters of bosoite are $a=13.8725(3), c=11.2694(3) \AA$ and $V=1878.18(8) \AA^{3}$. The refined fraction of each phase is as follows: $2.7 \mathrm{wt} . \%$ bosoite; $19 \mathrm{wt} . \%$ cubic chibaite; 76 wt.\% tetragonal chibaite; 0.9 wt.\% quartz; and 1.4 wt.\% calcite. Almost all PXRD data of chibaite samples showed the existence of $\sim 2-3$ wt.\% of bosoite. Diffraction data are shown in Fig. 4 and listed in Table 3.

Single-crystal X-ray diffraction (SXRD) studies were carried out using a Rigaku R-Axis Rapid II microdiffractometer with $\mathrm{CuK \alpha}$ radiation from the VariMax rotating-anode target combined with a confocal mirror. The epitaxial relation of bosoite and chibaite was confirmed from the holotype sample. However, due to overlap of diffraction peaks of chibaite and bosoite, even small volumes of chibaite associated with bosoite prevented us from doing the structure refinement of bosoite. As the two minerals cannot be distinguished under normal stereomicroscope, we had to make several thin sections to find and cut out a single-crystal of bosoite under polarised light. We decided not to consume the holotype for this purpose and used the cotype because the holotype is much better as a specimen but smaller than the cotype. The Rigaku RAPID AUTO software package (Rigaku, 1998) was used for processing the diffraction data, including the application of numerical absorption correction. The structure was solved by the charge flipping method using Superflip (Palatinus and Chapuis, 2007). From the electron-density distributions obtained by the charge flipping method, space group $P 6 / \mathrm{mmm}$ reported by Gerke and Gies (1984) was confirmed. All the framework atoms and two guest sites in the small cages were found by the charge flipping method. The rest of the guest sites were found by difference-Fourier syntheses. For the refinement of crystal structure, SHELXL-2018/1 software (Sheldrick, 2008, 2015) was used, with neutral atom-scattering factors. Details of the data 
Table 3. Powder X-ray data ( $d$ in $\AA$, I in \%) with normalised intensity of bosoite.

\begin{tabular}{|c|c|c|c|c|c|c|c|c|c|c|c|c|c|c|}
\hline$I_{\text {obs }}$ & $I_{\text {calc }}$ & $d_{\text {obs }}$ & $d_{\text {calc }}$ & $h k l$ & $l_{\text {obs }}$ & $I_{\text {calc }}$ & $d_{\mathrm{obs}}$ & $d_{\text {calc }}$ & $h k l$ & $l_{\text {obs }}$ & $I_{\text {calc }}$ & $d_{\mathrm{obs}}$ & $d_{\text {calc }}$ & $h k l$ \\
\hline * & 2.2 & 11.198 & 11.270 & 001 & * & 1.3 & & 3.004 & 400 & * & 9.8 & & 1.943 & 423 \\
\hline 5 & 3.4 & 8.215 & 8.219 & 101 & 4 & 3.3 & 2.894 & 2.894 & 213 & 5 & 7.0 & 1.887 & 1.887 & 602 \\
\hline 8 & 8.3 & 6.009 & 6.007 & 200 & 3 & 2.2 & 2.743 & 2.743 & 104 & * & 1.2 & & 1.867 & 315 \\
\hline 30 & 23.2 & 5.907 & 5.907 & 111 & 1.3 & 1.0 & 2.652 & 2.650 & 402 & * & 1.1 & & 1.864 & 432 \\
\hline * & 14.6 & 5.636 & 5.635 & 002 & & 1.9 & & 2.553 & 411 & 3 & 4.3 & 1.832 & 1.832 & 610 \\
\hline 10 & 12.9 & 4.541 & 4.541 & 210 & 3 & 5.9 & 2.403 & 2.403 & 500 & 2 & 2.3 & 1.787 & 1.787 & 334 \\
\hline 1.3 & 1.5 & 4.374 & 4.374 & 112 & 0.9 & 1.4 & 2.394 & 2.394 & 214 & * & 3.0 & & 1.768 & 424 \\
\hline 9 & 11.0 & 4.213 & 4.212 & 211 & * & $2.7,1.5$ & 2.350 & $2.350,2.346$ & 501,403 & * & 4.2 & & 1.748 & 433 \\
\hline 4 & 5.7 & 4.108 & 4.110 & 202 & 4 & 4.8 & 2.311 & 2.312 & 330 & * & 2.0 & & 1.745 & 325 \\
\hline 9 & 10.4 & 4.006 & 4.005 & 300 & 9 & 7.2 & 2.304 & 2.304 & 304 & 3 & 3.7 & 1.736 & 1.736 & 216 \\
\hline 44 & 44.2 & 3.773 & 3.774 & 301 & * & 3.7 & & 2.222 & 323 & * & 1.0 & & 1.714 & 441 \\
\hline * & 7.5 & & 3.757 & 003 & 1.7 & 1.5 & 2.210 & 2.210 & 502 & & 2.3 & & 1.701 & 306 \\
\hline $42^{\star}$ & $\begin{array}{r}33.6 \\
1.0\end{array}$ & 3.303 & $\begin{array}{l}\mathbf{3 . 3 0 3} \\
3.195\end{array}$ & $\begin{array}{l}\mathbf{1 1 3} \\
311\end{array}$ & 2 & $\begin{array}{l}1.2,1.3, \\
1.8\end{array}$ & 1.969 & $\begin{array}{l}1.971,1.970 \\
1.969\end{array}$ & $\begin{array}{l}601,324 \\
333\end{array}$ & & & & & \\
\hline
\end{tabular}

Theoretical powder data are calculated on the basis of the structural model refined by Rietveld analysis using RIETAN-FP. For unobserved or overlapped peaks, only calculated lines with $/>1$ are shown. The strongest lines are given in bold.

${ }^{*}$ These diffraction peaks were overlapped with peaks of other minerals in the powder sample, i.e. chibaite, quartz and calcite.

Table 4. Data collection and details of the single-crystal structural refinement.

\begin{tabular}{|c|c|c|}
\hline \multicolumn{3}{|l|}{ Crystal data } \\
\hline Structural formula & \multicolumn{2}{|l|}{$\mathrm{SiO}_{2} \cdot 0.50 \mathrm{CH}_{4}$} \\
\hline Space group & \multicolumn{2}{|l|}{$P 6 / m m m(\# 191)$} \\
\hline Unit-cell dimensions & \multicolumn{2}{|c|}{$a=13.9020(3), c=11.2802(2)$} \\
\hline Volume $\left(\AA^{3}\right)$ & \multicolumn{2}{|l|}{$V=1887.99(6)$} \\
\hline$z$ & \multicolumn{2}{|l|}{34} \\
\hline$D_{\text {calc }}\left(\mathrm{g} / \mathrm{cm}^{3}\right)$ & \multicolumn{2}{|l|}{2.04} \\
\hline$F 000$ & \multicolumn{2}{|l|}{1190} \\
\hline$\mu\left(\mathrm{mm}^{-1}\right)$ & \multicolumn{2}{|l|}{6.5} \\
\hline Crystal size $(\mathrm{mm})$ & \multicolumn{2}{|c|}{$0.060 \times 0.050 \times 0.040$} \\
\hline \multicolumn{3}{|l|}{ Data collection } \\
\hline Temperature (K) & \multicolumn{2}{|l|}{$293(2)$} \\
\hline Radiation & \multicolumn{2}{|c|}{$\operatorname{CuKa}(\lambda=1.54187 \AA)$} \\
\hline Voltage, current & \multicolumn{2}{|l|}{$40 \mathrm{kV}, 30 \mathrm{~mA}$} \\
\hline $2 \theta_{\max }\left(\left(^{\circ}\right)\right.$ & \multicolumn{2}{|l|}{136.4} \\
\hline No. of reflections measured & \multicolumn{2}{|l|}{22,203} \\
\hline Independent reflections $(I>2 \sigma(I))$ & \multicolumn{2}{|c|}{$739\left(705, R_{\text {int }}=0.031\right)$} \\
\hline Indices range of $h, k, l$ & \multirow{2}{*}{\multicolumn{2}{|c|}{$\begin{array}{l}-16 \leq h \leq 16,-16 \leq k \leq 16,-13 \leq l \leq 13 \\
\text { Numerical (NUMABS; Higashi, 1999) }\end{array}$}} \\
\hline Absorption correction & & \\
\hline Max. and min. transmission factors & \multicolumn{2}{|l|}{$0.710-0.771$} \\
\hline Refinement & Average model & Disordered model \\
\hline No. of variables / restraints & $73 / 0$ & $138 / 15$ \\
\hline Reflection/Parameter Ratio & 10.1 & 5.36 \\
\hline$R_{1}, \mathrm{w} R_{2}(I>2 \sigma(I))$ & $0.043,0.120$ & $0.030,0.085$ \\
\hline$R_{1}, W R_{2}$ (All reflections) & $0.044,0.121$ & $0.030,0.086$ \\
\hline Goodness-of-fit: & 1.17 & 1.09 \\
\hline$\Delta \rho_{\max }, \Delta \rho_{\min }\left(e^{-} / \AA^{3}\right)$ & 0.55 and -0.34 & 0.43 and -0.27 \\
\hline
\end{tabular}

collection, refinement, and results of the refinement are summarised in Table 4.

An illustration of the average crystal structure is shown in Fig. 5. Refined atomic coordinates and equivalent isotropic displacement parameters are summarised in Table 5. Selected bond distances and bond angles are given in Table 6. From the difference-Fourier map, all of oxygen atom positions were found to be split around their average positions. Subsequent refinements with all the $\mathrm{O}$ sites split around their average positions greatly reduced the residual electron densities and improved $R 1$ from $4.26 \%$ to $2.96 \%$ with a trade-off of poorer data / parameter ratio. The mean $U_{\text {eq }}$ of $\mathrm{O}$ sites also changed from $0.076 \AA^{2}$ to $0.039 \AA^{2}$. To reduce the number of free parameters and their correlations, occupancy of each split $O$ site was fixed at $1 / 3$ and the position of each $\mathrm{O}$ site was restrained such that it is placed equidistant from neighbouring Si sites. Anisotropic displacement components of the split $\mathrm{O}$ atoms along the adjacent $\mathrm{O}-\mathrm{O}$ direction were also restrained to be equal by using the DELU instruction. The crystallographic information files containing results of the refinements based on the average and split models have been deposited with the Principal Editor of Mineralogical Magazine and are available as Supplementary material (see below).

The unit cell of bosoite consists of three types of cages: two $\left[4^{3} 5^{6} 6^{3}\right]$ cages, three $\left[5^{12}\right]$ cages and one $\left[5^{12} 6^{8}\right]$ cage (here $\left[4^{i} 5^{j} 6^{k}\right]$ denotes a polyhedron having $i$ quadrilateral, $j$ pentagonal and $k$ hexagonal faces). The former two types of cages are relatively small and mainly occupied by $\mathrm{CH}_{4}$. $\mathrm{C} 1$ and $\mathrm{C} 2$ atoms are those of $\mathrm{CH}_{4}$ molecules at the centre of $\left[4^{3} 5^{6} 6^{3}\right]$ and $\left[5^{12}\right]$ cages respectively, and their $U_{\text {eq }}$ are relatively large owing to very weak van der Waals interaction with the host framework. Occupancies of these sites were fixed at 1 because they exceeded 1 when freely refined. Furthermore, the difference-Fourier map still showed small residuals around $\mathrm{C} 1$ and $\mathrm{C} 2$ atoms. Distances from $\mathrm{C} 1$ and $\mathrm{C} 2$ atoms to the residuals were $\sim 1 \AA$ and these residuals were interpreted as orientationally disordered hydrogen atoms of $\mathrm{CH}_{4}$. When these $\mathrm{H}$ atoms were included in the refinement with their $U_{\text {iso }}$ values constrained to the same and C-H distances fixed to $1.08 \AA, R$ indices decreased $\sim 0.3 \%$. In the final refinement of the average model, these $\mathrm{H}$ atoms are not included because they are less reliable, whereas they are included in the split model for reference. In the largest $\left[5^{12} 6^{8}\right]$ cage, large 


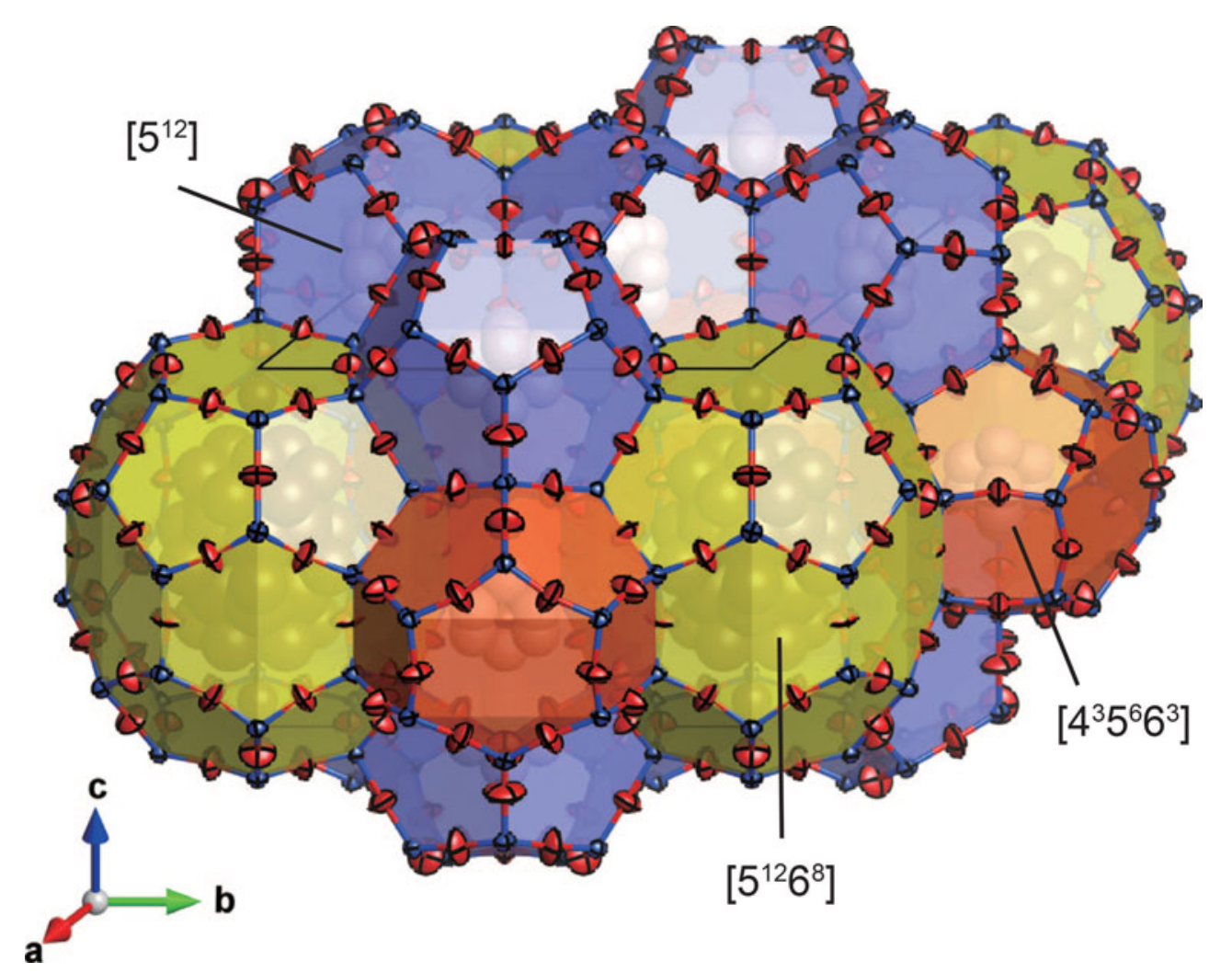

Fig. 5. The average framework structure of bosoite refined without splitting of $O$ sites.

Table 5. Refined atomic position and equivalent isotropic displacement parameters $\left(\AA^{2}\right)$ of the average model.

\begin{tabular}{lllllll}
\hline & Wyk. & \multicolumn{1}{c}{$x$} & \multicolumn{1}{c}{$y$} & \multicolumn{1}{c}{$z$} & $U_{\text {eq }} / U_{\text {iso }}$ & Occ. \\
\hline Si1 & 120 & $0.41870(9)$ & $0.20935(4)$ & $0.22527(9)$ & $0.0300(4)$ & 1 \\
Si2 & $12 n$ & $0.38736(8)$ & $0.38736(8)$ & $0.36254(9)$ & $0.0305(4)$ & 1 \\
Si3 & $6 l$ & $0.26279(12)$ & $0.13140(6)$ & 0 & $0.0296(4)$ & 1 \\
Si4 & $4 h$ & $2 / 3$ & $1 / 3$ & $0.13850(15)$ & $0.0318(5)$ & 1 \\
O1 & $24 r$ & $0.3946(3)$ & $0.2885(2)$ & $0.3036(3)$ & $0.0786(10)$ & 1 \\
O2 & 120 & $0.5438(3)$ & $0.27189(15)$ & $0.1844(4)$ & $0.0836(14)$ & 1 \\
O3 & 120 & $0.3394(3)$ & $0.16968(17)$ & $0.1142(3)$ & $0.0724(12)$ & 1 \\
O4 & $6 k$ & $0.3616(4)$ & 0 & $1 / 2$ & $0.0611(15)$ & 1 \\
O5 & $6 j$ & $0.1850(4)$ & 0 & 0 & $0.0651(15)$ & 1 \\
O6 & $6 i$ & $1 / 2$ & 0 & $0.3425(5)$ & $0.0725(18)$ & 1 \\
O7 & $2 c$ & $2 / 3$ & $1 / 3$ & 0 & $0.102(4)$ & 1 \\
C1 & $2 d$ & $1 / 3$ & $2 / 3$ & $1 / 2$ & $0.127(9)$ & 1 \\
C2 & $3 f$ & $1 / 2$ & 0 & 0 & $0.137(8)$ & 1 \\
C3A & $2 e$ & 0 & 0 & $0.265(9)$ & $0.28(7)^{\star}$ & $0.73(14)$ \\
C3B & 120 & $-0.044(3)$ & $0.044(3)$ & $0.571(6)$ & $0.28^{\star}$ & $0.30(3)$ \\
C3C & $12 n$ & 0 & $0.112(6)$ & $0.315(6)$ & $0.28^{*}$ & $0.33(3)$ \\
C3D & $2 e$ & 0 & 0 & $0.06(2)$ & $0.28^{\star}$ & $0.21(6)$ \\
C3E & $6 m$ & $0.177(8)$ & $0.088(4)$ & $1 / 2$ & $0.28^{\star}$ & $0.50(6)$ \\
\hline
\end{tabular}

${ }^{*} U_{\text {iso }}$ were refined with their values constrained to the same.

molecules or multiple number of small molecules are included. The total site-scattering factor in the $\left[5^{12} 6^{8}\right]$ cage, refined as occupancies of $\mathrm{C}$, was $81 e^{-}$. The refined $U_{\text {iso }}$ of C3A to C3E in the $\left[5^{12} 6^{8}\right]$ cage are extremely large owing to the variety of guest species and their static/dynamic disorder. Therefore, guest species and their ratio in the $\left[5^{12} 6^{8}\right]$ cage could not be interpreted. Depending on average degree of polymerisation for alkanes, 81 $e^{-}$corresponds to $8.1 \mathrm{CH}_{4}, 4.5 \mathrm{C}_{2} \mathrm{H}_{6}, 3.12 \mathrm{C}_{3} \mathrm{H}_{8}$, or $2.38 \mathrm{C}_{4} \mathrm{H}_{10}$ molecules. When these four cases are considered, the total
Table 6. Selected bond distances and bond angles in bosoite.

\begin{tabular}{|c|c|c|c|}
\hline & Distance $(\AA ̊)$ & & Angle $\left({ }^{\circ}\right)$ \\
\hline $\mathrm{Si1}-\mathrm{O} 1 \times 2$ & $1.573(2)$ & Si1-01-Si2 & $167.7(2)$ \\
\hline $\mathrm{Si} 1-\mathrm{O} 2$ & $1.575(4)$ & $\mathrm{Si} 4-\mathrm{O} 2-\mathrm{Si} 1$ & $177.7(4)$ \\
\hline $\mathrm{Si1}-\mathrm{O} 3$ & $1.575(3)$ & $\mathrm{Si1}-\mathrm{O} 3-\mathrm{Si} 3$ & $178.3(3)$ \\
\hline $\mathrm{Si} 2-\mathrm{O} 1 \times 2$ & $1.574(2)$ & $\mathrm{Si2}-\mathrm{O} 4-\mathrm{Si} 2$ & $154.0(4)$ \\
\hline $\mathrm{Si} 2-06$ & $1.5821(13)$ & $\mathrm{Si3}-05-\mathrm{Si} 3$ & $167.8(4)$ \\
\hline $\mathrm{Si} 2-\mathrm{O} 4$ & $1.5914(15)$ & $\mathrm{Si} 2-06-\mathrm{Si} 2$ & $163.6(4)$ \\
\hline $\mathrm{Si} 3-\mathrm{O} 3 \times 2$ & $1.584(3)$ & $\mathrm{Si} 4-07-\mathrm{Si} 4$ & 180 \\
\hline $\mathrm{Si} 3-05 \times 2$ & $1.5909(10)$ & & \\
\hline Si4-07 & $1.5623(17)$ & & \\
\hline $\mathrm{Si} 4-\mathrm{O} 2 \times 3$ & $1.568(4)$ & & \\
\hline$<\mathrm{Si}-\mathrm{O}>$ & 1.578 & $<\mathrm{Si}-\mathrm{O}-\mathrm{Si}>$ & 170 \\
\hline
\end{tabular}

number of guest $\mathrm{C}$ atoms in the unit cell is $\sim 13.1-14.5$. Assuming that widely spread electrons of $\mathrm{H}$ atoms in the $\left[5^{12} 6^{8}\right]$ cage were not fully reflected to the refined site-scattering factor, and the $\left[5^{12} 6^{8}\right]$ cage is occupied mainly by large hydrocarbons, these numbers are within an acceptable range compared to the number estimated by the chemical analysis (17C per unit cell).

The electron-density distribution in bosoite calculated by the maximum entropy method (MEM) is shown in Fig. 6. Dysnomia (Momma et al., 2013) with the L-BFGS algorithm was used for calculation and VESTA (Momma and Izumi, 2011) was used for visualisation. To reduce correlation of residuals $\left|F_{\mathrm{o}}-F_{\mathrm{c}}\right| / \sigma\left(F_{\mathrm{o}}\right)$ with $d$ spacing of reflections, an exponential-type weighting scheme proportional to $m \times \exp (-A / d)$ was used, where $m$ is multiplicity of reflections and $A$ is a weighting parameter optimised as 12.7. The electron-density distribution also confirms that all cages are almost fully occupied. 


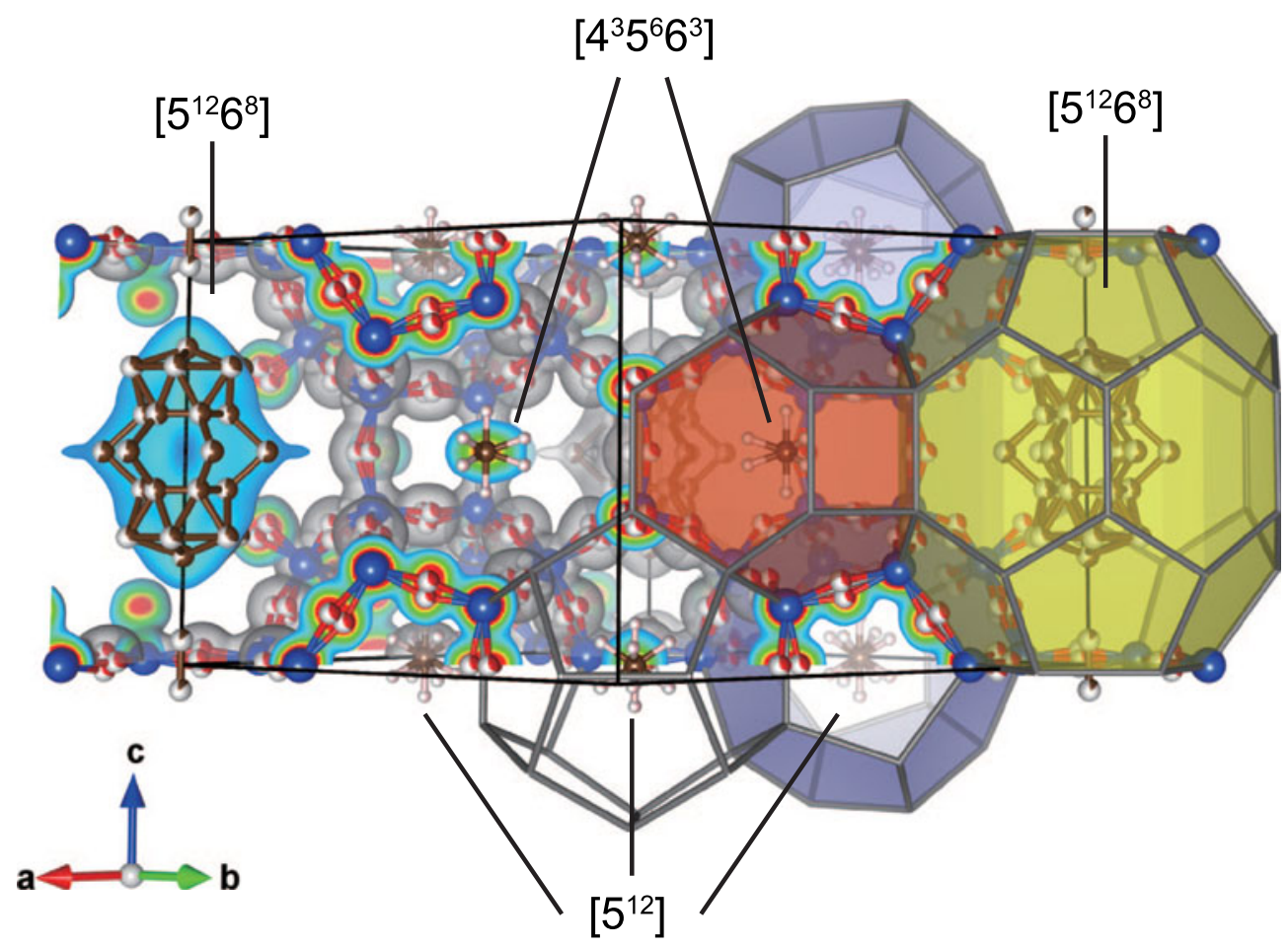

Fig. 6. Electron-density distribution in bosoite determined by MEM analysis overlapped with the split atom model. Isosurface level is $0.5 e^{-} / \AA^{3}$.

\section{Discussion}

The order of crystallisation of melanophlogite, chibaite and bosoite observed in the present study indicates a decisive role of guest molecules on their crystallisation. The $\left[5^{12}\right]$ cage is common to all three minerals. Other types of cages making-up these minerals are: the $\left[5^{12} 6^{2}\right]$ cage in melanophlogite, the $\left[5^{12} 6^{4}\right]$ cage in chibaite as well as the $\left[4^{3} 5^{6} 6^{3}\right]$ and the $\left[5^{12} 6^{8}\right]$ cages in bosoite. The $\left[5^{12} 6^{8}\right]$ cage is the largest and the $\left[5^{12}\right]$ cage is the smallest among them, whereas the $\left[4^{3} 5^{6} 6^{3}\right]$ cage is comparable in size to the smallest $\left[5^{12}\right]$ cage. From the previous studies on syntheses of these clathrasils, the presence of large molecules matching in size to the largest cage in the crystal structure is considered as a necessary condition for their crystallisation (e.g. van Koningsveld and Gies, 2004). This model can explain why bosoite was always found associated with chibaite crystals and why it is so minor in volume compared to the other two. The $\left[5^{12} 6^{2}\right]$ cage in melanophlogite can incorporate small gas molecules such as $\mathrm{CH}_{4}, \mathrm{CO}_{2}, \mathrm{~N}_{2}$ and $\mathrm{H}_{2} \mathrm{~S}$, which are abundant gases in Nature. As a result, among these clathrasils, melanophlogite is the most abundant and the first phase to crystallise in Nature. While $\mathrm{C}_{2} \mathrm{H}_{6}$ is also capable of fitting into the $\left[5^{12} 6^{2}\right]$ cage (Ohno et al., 2009), $\mathrm{C}_{3} \mathrm{H}_{8}$ or larger hydrocarbons are too large for melanophlogite. As a result, the concentration of these large molecules in hydrothermal solutions increases as melanophlogite crystallises, and eventually crystallisation of chibaite is initiated. Similarly, the increase of the concentration of even larger molecules that cannot fit into the chibaite structure would initiate crystallisation of bosoite. As bosoite grows, large molecules would be consumed easily and overgrowth of chibaite on bosoite also occurs. Larger hydrocarbons have higher molecular refraction. Therefore, the above model of crystallisation is also consistent with the fact that the refractive index of bosoite is higher than that of chibaite regardless that the framework density of bosoite is lower than that of chibaite.
Our observation that melanophlogite was almost always found to be replaced by quartz indicates that melanophlogite is less stable than both chibaite and bosoite.

$\mathrm{SiO}_{4}$ tetrahedra in framework silicates are known to be very stiff, to a first approximation they behave more like rigid units which rotate and translate without distortion of the tetrahedra (Hammonds et al., 1996). On the other hand, the apparently short $\mathrm{Si}-\mathrm{O}$ distances are often reported for clathrasils as a consequence of local tilting of the $\mathrm{SiO}_{4}$ tetrahedra with the rigid-unit mode, where $\mathrm{Si}-\mathrm{O}$ distances are almost constant but actual $\mathrm{O}$ atoms are distributed around the refined positions (Momma, 2014). This is why in the refinement of bosoite without splitting of $\mathrm{O}$ sites, the mean value of $\mathrm{Si}-\mathrm{O}$ distance $(1.578 \AA$ ) apparently looks shorter than the predicted value, $1.609 \AA$, for tetrahedrally coordinated pure silica frameworks (Brown et al., 1969; Wragg et al., 2008). Si-O-Si angles range from $154.0(4)^{\circ}$ to $180^{\circ}$ with a mean value of $170^{\circ}$, which is also larger than the average value of $154^{\circ} \pm 9$ for pure silica zeolite frameworks (Wragg et al., 2008). With the splitting of $\mathrm{O}$ sites, mean values of $\mathrm{Si}-\mathrm{O}$ distances and $\mathrm{Si}-\mathrm{O}-\mathrm{Si}$ angles changed to $1.604 \AA$ and $156^{\circ}$ respectively. The splitting of $\mathrm{O}$ sites due to local disorder has also been reported for synthetic MTN- and DOH-type clathrasils (Könnecke et al., 1992; Miehe et al., 1993). In the case of melanophlogite and chibaite, the tilting of the framework $\mathrm{SiO}_{4}$ tetrahedra at ambient or low temperature causes lowering of their space group symmetries (e.g. Nakagawa et al., 2001; Scheidl et al., 2018). On the other hand, as was reported for the synthetic DOH-type clathrasil (Miehe et al., 1993), we could see no sign of symmetry lowering of bosoite even though all of the $\mathrm{O}$ sites were found to be split.

Supplementary material. To view supplementary material for this article, please visit https://doi.org/10.1180/mgm.2020.91 
Acknowledgements. We are grateful to Drs Masahiko Tanaka and Yoshio Katsuya for their support at BL15XU SPring-8 (Proposal No. 2007A4503) and Mr. Taiji Oyama of JASCO for his arrangement on Raman spectroscopy measurement at JASCO Laboratory. The authors also thank Dr Stuart Mills, Principal Editor and two anonymous reviewers for critical comments and suggestions. The preliminary SXRD data was obtained by KEK photon factory BL10A (PAC. No. 2012G112, 2014G173). This study was supported partially by JSPS KAKENHI Grant Numbers JP24740359 and JP16H05742.

\section{References}

Baerlocher C., McCusker L.B. and Olson D.H. (2007) Atlas of Zeolite Framework Types. Elsevier, Amsterdam.

Brown G.E., Gibbs G.V. and Ribbe P.H. (1969) The nature and variation in length of the $\mathrm{Si}-\mathrm{O}$ and $\mathrm{Al}-\mathrm{O}$ bonds in framework silicates. American Mineralogist, 54, 1044-1061.

Gerke H. and Gies H. (1984) Studies on clathrasils. IV: Crystal structure of dodecasil $1 \mathrm{H}$, a synthetic clathrate compound of silica. Zeitschrift für Kristallographie, 166, 11-22.

Gies H. (1984) Studies on Clathrasils. VI. Crystal structure of dodecasil 3C, another synthetic clathrate compound of silica. Zeitschrift für Kristallographie, 167, 73-82.

Gies H. and Marker B. (1992) The structure-controlling role of organic templates for the synthesis of porosils in the systems $\mathrm{SiO}_{2} /$ template $/ \mathrm{H}_{2} \mathrm{O}$. Zeolites, 12, 42-49.

Gies H., Gerke H. and Liebau F. (1982) Chemical composition and synthesis of melanophlogite, a clathrate compound of silica. Neues Jahrbuch für Mineralogie, Monatshefte, 3, 119-124.

Hammonds K.D., Dove M.T., Giddy A.P., Heine V. and Winkler B. (1996) Rigid-unit phonon modes and structural phase transitions in framework silicates. American Mineralogist, 81, 1057-1079.

Higashi, T. (1999) NUMABS. Rigaku Corporation, Tokyo, Japan.

Izumi F. and Momma K. (2007) Three-dimensional visualization in powder diffraction. Solid State Phenomena, 130, 15-20.

Kamb B. (1965) A clathrate crystalline form of silica. Science, 148, 232-234.

Kanzaki M. (2019) High-temperature Raman spectroscopic study of $\mathrm{CO}_{2}$-containing melanophlogite. Journal of Mineralogical and Petrological Sciences, 114, 122-129.

Kolesov B.A. and Geiger C.A. (2003) Molecules in the $\mathrm{SiO}_{2}$-clathrate melanophlogite: a single-crystal Raman study. American Mineralogist, 88, 1364-1368.

Könnecke M., Miehe G. and Fuess H. (1992) Static disorder of dodecasil 3C. A single-crystal study with synchrotron radiation. Zeitschrift für Kristallographie, 201, 147-155.

Likhacheva A.Y., Goryainov S.V., Seryotkin Y.V., Litasov K.D. and Momma K. (2016) Raman spectroscopy of chibaite, natural MTN silica clathrate, at high pressure up to $8 \mathrm{GPa}$. Microporous and Mesoporous Materials, 224, 100-106.

Lu H., Seo Y.-T., Lee J.-W., Moudrakovski I., Ripmeester J. A., Chapman N.R., Coffin R.B., Garder G. and Pohlman J. (2007) Complex gas hydrate from the Cascadia margin. Nature, 445, 303-306.

Miehe G., Vogt T., Fuess H. and Müller, U. (1993) A study of disorder in the $\mathrm{SiO}_{2}$ host lattice of dodecasil $1 \mathrm{H}$ using synchrotron radiation. Acta Crystallographica, B49, 745-754.

Momma K. (2014) Clathrate compounds of silica. Journal of Physics: Condensed Matter, 26, 103203.

Momma K. and Izumi F. (2011) VESTA 3 for three-dimensional visualization of crystal, volumetric and morphology data. Journal of Applied Crystallography, 44, 1272-1276.
Momma K., Ikeda T., Nishikubo K., Takahashi N., Honma C., Takada M. Furukawa Y., Nagase T. and Kudoh Y. (2011) New silica clathrate minerals that are isostructural with natural gas hydrates. Nature Communications, 2, 196.

Momma K., Ikeda T., Belik A.A. and Izumi, F. (2013) Dysnomia, a computer program for maximum-entropy method (MEM) analysis and its performance in the MEM-based pattern fitting. Powder Diffraction, 28, 184-193.

Momma K., Ikeda T., Nagase T., Kuribayashi T., Honma C., Nishikubo K., Takahashi N., Takada M., Matsushita Y., Miyawaki R. and Matsubara S. (2014) Bosoite, IMA 2014-023. CNMNC Newsletter No. 21, August 2014, page 800; Mineralogical Magazine, 78, 797-804.

Nakagawa T., Kihara K. and Harada K. (2001) The crystal structure of low melanophlogite. American Mineralogist, 86, 1506-1512.

Ogawa Y. and Ishimaru K. (1991) Geological structures of the Emi Group on the coast of the Emi area, southern part of the Boso Peninsula, Central Honshu. Journal of Geography, 100, 530-539 [in Japanese with English abstract].

Ohno H., Strobel T.A., Dec S.F., Sloan E.D. and Koh, C.A. (2009). Raman studies of methane-ethane hydrate metastability. Journal of Physical Chemistry A, 113, 1711-1716.

Palatinus, L. and Chapuis G. (2007) SUPERFLIP- a computer program for the solution of crystal structures by charge flipping in arbitrary dimensions. Journal of Applied Crystallography, 40, 786-790.

Rigaku (1998) RAPID-AUTO. Rigaku Corporation, Tokyo, Japan.

Scheidl K.S., Effenberger H.S., Yagi T., Momma K. and Miletich, R. (2018) The hydrocarbon-bearing clathrasil chibaite and its host-guest structure at low temperature. IUCrJ, 5, 595-607.

Sheldrick G.M. (2008) A short history of SHELX. Acta Crystallographica, A64, 112-122.

Sheldrick G.M. (2015) Crystal structure refinement with SHELXL. Acta Crystallographica, C71, 3-8.

Shimanouchi T. (1972) Tables of Molecular Vibrational Frequencies, Consolidated Volume I. National Bureau of Standards, Gaithersburg, MD, USA.

Skinner B.J. and Appleman, D.E. (1963) Melanophlogite, a cubic polymorph of silica. American Mineralogist, 48, 854-867.

Subramanian S., Kini R.A., Dec S.F. and Sloan E.D. (2000) Evidence of structure II hydrate formation from methane + ethane mixtures. Chemical Engineering Science, 55, 1981-1999.

Sum A.K., Burruss R.B. and Sloan E.D. (1997) Measurement of clathrate hydrates via Raman spectroscopy. Journal of Physical Chemistry B, 101, 7371-7377.

Takahashi N., Shibata K., Hirata D. and Niida S. (2016). Geologic traverse from the Mineoka Belt to the Hayama Belt, Central Japan. Journal of the Geological Society of Japan, 122, 375-395 [in Japanese].

Tribaudino M., Artoni A., Mavris C., Bersani D., Lottici P.P. and Belletti D. (2008) Single-crystal X-ray and Raman investigation on melanophlogite from Varano Marchesi (Parma, Italy). American Mineralogist, 93, 88-94.

van Koningsveld H. and Gies H. (2004) Similarities between the clathrasils DOH, DDR, MEP and MTN. Zeitschrift für Kristallographie, 219, 637-643.

von Lasaulx A. (1876) Mineralogisch-krystallographische Notizen. VII Melanophlogit, ein neues Mineral. Neues Jahrbuch für Mineralogie, 250257.

Wragg D.S., Morris R.E. and Burton, A.W. (2008) Pure silica zeolite-type frameworks: A structural analysis. Chemistry of Materials, 20, 1561-1570.

Yagi T., Iida E., Hirai H., Miyajima N., Kikegawa T. and Bunno, M. (2007) High-pressure behavior of a $\mathrm{SiO}_{2}$ clathrate observed by using various pressure media. Physical Review B, 75, 174115. 